\title{
Biomechanical Particularities in the Therapy of the Rheumatic Knee
}

\author{
Christoph Biehl 1,2,*(D), Martin Heinrich 1,2 ${ }^{10}$, Lotta Biehl ${ }^{3}$, Gero Knapp ${ }^{1,2}$, Christian Heiss ${ }^{1,2}$ \\ and Ulrich Thormann 1,2 \\ 1 Department of Trauma, Hand and Reconstructive Surgery, University Hospital Giessen, \\ 35392 Giessen, Germany; martin.heinrich@chiru.med.uni-giessen.de (M.H.); \\ gero.knapp@chiru.med.uni-giessen.de (G.K.); christian.heiss@chiru.med.uni-giessen.de (C.H.); \\ ulrich.thormann@chiru.med.uni-giessen.de (U.T.) \\ 2 Experimental Trauma Surgery, Justus-Liebig-University of Giessen, 35392 Giessen, Germany \\ 3 Medical Faculty Heidelberg of Heidelberg University, 69117 Heidelberg, Germany; lotta.biehl@gmx.de \\ * Correspondence: Christoph.biehl@chiru.med.uni-giessen.de; Tel.: +49-(0)641-985-58971
}

Received: 2 November 2020; Accepted: 28 November 2020; Published: 1 December 2020

\begin{abstract}
In rheumatoid arthritis, the joints of the lower extremities are almost always affected. This is most conspicuous in the knee joint. In rheumatics, inflammatory osteoarthritis manifests itself comparably earlier than in patients with osteoarthritis. The focus of attention was primarily on the synovia with its destruction process and secondary changes. Now, driven by experimental research, dendritic cells and fibroblasts and molecular features are moving into the clinician's field of vision. Even in joints that appear to be in remission with no swelling or pain, the activity of these cells leads to changes in the capsule-ligaments. The complex deformities and instabilities caused by this, in conjunction with atrophy of the inter-articular musculature, have an impact on the activities of daily life (ADL). If these biomechanical aspects of the knee joint are not taken into account early on in therapy, the frequency of primary and secondary surgical treatment increases. The timely recognition of biomechanical pathologies and consistent treatment can contribute to improving the patient situation in addition to adequate medication therapy.
\end{abstract}

Keywords: sarcopenia; rheumatoid arthritis synovial fibroblast (RASF); biomechanics; knee; knee surgery; rheumatoid arthritis; register of complications; Orthopaedisch Rheumatologische Jahresuntersuchung (ORJ)

\section{Introduction}

Rheumatoid arthritis (RA) is an inflammatory autoimmune disease that affects the knee joints in over $90 \%$ of patients. Kerschbaumer distinguishes between two different forms of the disease with different biomechanical characteristics [1]. Patients with juvenile arthritis or seronegative arthritis are prone to secondary anomalies and early destruction of the joints and subsequently to contractures. In typical adult RA, direct and indirect damage to the capsule and ligaments occurs without movement deficits. The joints with elongated ligaments decenter early and lead to destruction of the articular surfaces. If the changes occur gradually and over a longer time, the affected persons are nevertheless considerably restricted in their mobility. The activity of an inflammatory gonarthritis with a proliferating synovialis does not necessarily have to be accompanied by a visible thickening of the capsule and effusion formation. Pronounced states of swelling are easily recognizable, but these need not be exclusively articular. Venous or lymphatic congestion also leads to edema and impresses with a similar clinical picture. Progress in understanding the signaling pathways that control disease activity and the course of inflammatory changes at the intra- and intercellular level has made efficient therapy 
possible [2-4]. This leads to a significant reduction in inflammatory activity and thus more patients achieve remission. However, individual "rebellious" joints may not respond to the drug therapy or may not respond sufficiently. The periarticular structures are also directly damaged by inflammatory mediators. Seemingly inconspicuous findings elude the course of diagnosis of the Disease Activity Score 28 (DAS28), as they remain under the radar of the rheumatologist. For this reason, regular monitoring of joints and periarticular structures not covered by the DAS28 is important, especially in the case of tendons and ligaments. As an extension/supplement to the DAS28, the annual orthopedic rheumatological examination (ORJ) records such pathologies and enables the physician to include them in the therapy concept [5].

A concept for the therapy of rheumatoid knee joint manifestations must take into account conservative and surgical treatment of the knee joint according to the stage of the disease and take into account the individual characteristics of the patient [6,7]. It is up to the therapist to adapt these according to his or her level of knowledge and to carefully weigh the potential risks against the benefits $[1,8]$. Problems and complications can occur earlier and more severely in the knee joint than in osteoarthritic patients due to the limited compensation possibilities offered by the adjacent joint, which is usually also affected.

Following an overview of the pathogenesis of RA in the joint, the article describes the biomechanical changes and peculiarities of the rheumatoid knee and provides a current summary of conservative and operative therapy.

Current publications have been acquired according to the recommendations for systematic reviews via PubMed, PubMed Central, and google scholar. The search strategy included the keywords biomechanics, biomechanical problems, biomechanical pathologies, ligament balancing, instabilities, self-healing, natural antioxidants, and anti-inflammatory. The search was narrowed down using the keywords knee joint and rheumatoid arthritis. From an initial total of more than 22,000 articles, up to 65 were left, of which up to 37 were included in this manuscript [9].

\section{Cellular and Molecular Mechanisms of Joint Manifestation}

For a long time, the biomechanical characteristics of RA in the knee joint were exclusively seen as associated with synovitis, swelling, and chronic overloading of the capsule-ligaments. However, a generalized chronic disease is not limited to single cells. New research on the mechanisms of RA has shown the involvement of periarticular cells and structures in the disease, which have not been the focus of surgeons until now. Generalized existing autoantibodies, such as anti-citrullinated protein antibodies (ACPA) and cytokines maintain the production of inflammatory mediators in addition to synovial fibroblasts and lead to oxidative stress. ACPAs have been shown in controlled studies to be good predictors of rapid progressive joint destruction due to erosive arthritis. The heterogeneity of gene expression also leads to altered cell lines such as fibroblast-like synovial cells (FLS), or mast cells maintain the inflammatory destructive processes of joint damage $[10,11]$. Fibroblasts and FLS and their interaction with cells of the immune system such as neutrophils and T cells play a key role in the inflammatory destructive processes of the joints. In the early phase of the disease, an increased number of neutrophils can be detected. They increase the oxidative stress in the tissue, can form neutrophil extracellular traps (NETs), and at the same time promote the citrullination of arginine via an intracellular activation of peptidyl arginine deiminase-4 (PAD4) and store it in the NETs [12,13]. Compared to patients with osteoarthritis, the oxidative stress in the tissue of rheumatic patients is significantly higher $[14,15]$. ACPAs, with a specificity of $97 \%$ for RA, can be detected in the blood up to 10 years before the manifestation of RA. In the case of macroscopic findings, this should entail a histopathological workup of the synovial tissue to detect developing RA at an early stage $[16,17]$. ACPAs activate FLS, which in turn present $T$ cells to NET-citrullinated peptides and lead to autoimmunity [18]. In the joint, excessive proliferation of FLS leads to hyperplastic pannus and increased secretion of chondrotoxic mediators such as matrix metalloproteinases (MMP). As a result, direct and indirect irreversible damage to the joint surfaces occurs, which is detectable even with sufficient basic therapy [19]. FLS also secrete 
vasoactive and immunomodulating molecules that can induce periarticular vasculitis and promote differentiation of osteoclasts by activating Receptor Activator of NF-KB Ligand (RANK-L) [20,21]. Regulation and modulation of these molecules are performed by CD4+ T-helper cells. The disturbed function of the cells leads to an increase in interleukins in the tissue, which is significantly higher than in osteoarthritis [22]. Changes can also be found at the RNA level. Gene polymorphisms and an altered microbiome lead to altered free microRNA (miRNA) as an adaptation of epigenetic mechanisms, which interferes with RNA transcription $[23,24]$. Current research in connection with SARS-CoV2 makes use of these polymorphisms in a therapeutic approach [25].

\section{Biomechanics and Clinic of the Rheumatic Knee}

The knee joint is a joint guided by a capsule, ligaments, and muscles, which performs a roll-slide movement with final rotation. The coordinated interaction and integration of the elements is essential for smooth functioning. The inflammatory changes in RA with proliferation of synovial cells (FLS), pannus formation, and secretion of chondro-destructive MMP lead to capsular swelling with chronic overuse of the capsule-ligament structures. At the same time dendritic cells, including osteoblasts and osteocytes, are damaged by MMP and ACPA in cell adhesion and integration. Osteoclastoneo-genesis is enhanced by activation of RANK-L $[21,26]$. This results in a weakening of the periarticular capsule-band approaches and subchondral osteoporosis with marginal erosions and usures [16,27]. Approximately $80 \%$ of rheumatic patients have a malalignment of the knee. Muscular deterioration with loss of strength in the sense of sarcopenia can be demonstrated in isokinetic studies, particularly of the extensors, which promotes the disbalance [28]. In contrast to patients with osteoarthritis with impairment of one knee, rheumatics involve several joints of the lower extremities in the disease process. Pain and arthritic changes in the pelvis and ipsilateral hip lead to changes in the kinematics of the knee joint, as do deformities of the hindfoot as a result of posticus insufficiency [29-32]. The supposedly well-intentioned protection impairs the overall mobility of patients in the long term. Persistent dysfunctions and imbalances of the knee also cause long-term damage to the contralateral ankle [33]. The disturbed kinematics leads to cartilage destruction and gonarthritis, which is often laterally accentuated. Tendon ruptures can occur in pre-damaged tendons after supposedly simple surgical procedures, but also after minor injuries. For this reason, open access to the knee joint must be used with appropriate care to protect the structures. The repair mechanisms of tendon healing are irritated or even suppressed by immunosuppressive drugs [34].

Already in the early stages acc. to Larsen, Dale and Eek (LDE 0-1), periarticular rarefied bone structure can be detected at the border lamella using high-resolution MRI (or by the pathologist). Spatially close areas of osteo-necrotic and osteoclastic regions in the bone near the joint are found primarily in psoriatic patients. Looser remodeling zones are near the joint in cases of vitamin D deficiency. The conservative therapy includes, in addition to relief and capsule-ligament protection using an orthosis, vitamin D substitution.

Changes in the cartilage and bone close to the joint lead to changes in the kinematics at an early stage. Under these conditions, a correction of knee problems will tend to lead to recurrences in order not to endanger the patient's overall mobility [35].

\section{Conservative Therapy}

According to the current recommendations of the American College of Rheumatology (ACR)/European League Against Rheumatism (EULAR), a treat-to-target strategy in the treatment of RA is being implemented today [36]. The aim here is early diagnosis and early therapy according to the principle of "hit hard and early", under which secondary damage to joints could be significantly reduced. An improved course of the disease can detect therapy failures earlier, which is due to the heterogeneity of rheumatoid arthritis synovial fibroblast (RASF) in particular. Therapy can therefore be adapted earlier than was possible just a few years ago, away from the systemic administration of oral corticoids and cell line depletors (e.g., rituximab = RTX), towards antibody therapy against 
inflammation mediators or small molecule inhibition (Janus kinase inhibitors) [11]. In particular, the wider range of biological disease-modifying antirheumatic drugs (bDMARDs) and targeted synthetic DMARDs (tsDMARDs) is giving a boost to drug therapy in the direction of individualization and specification [11,27]. Over the last decades, these measures have led to a reduction of up to $90 \%$ in the number of rheumatism related operations [37,38]. The international consensus for perioperative drug therapy has been adapted accordingly in individual countries $[39,40]$. These also depend on the experience of complications experienced by surgeons [41,42]. Independent registry data make a valuable contribution to the continuous improvement of the patient's situation [43]. Compared to patients with osteoarthritis, rheumatics show a higher level of satisfaction and, at the same time, a measurably poorer function of surgically treated joints such as the knee $[44,45]$.

In osteoarthritis, in particular, alternative therapeutic approaches are now increasingly gaining interest to activate self-healing powers [46-48]. In most cases, these are limited first and foremost to changes in diet and diets that reduce inflammatory cytokines and oxidative mediators $[23,46]$. Individual ingredients have been characterized in more detail. Tripterygium wilfordii Hook F (TwHF), for example, shows comparable effects to methotrexate (MTX), but the bioavailability of these natural substances is still poor [49]. In the future, this could be improved by packaging the substances in nanoparticles. Flavonoids, which are used against oxygen radicals, can modulate intracellular signaling pathways [50]. Piperine (alkaloid of pepper) inhibits prostaglandine E2 (PGE2) [51]. The treatment of chronic pain with cannabinoids has also increased in recent years. Studies have been able to detect cannabis receptors in inflammatory synovia, which allows for targeted complementary pain management [52]. However, many of these results may not be easily transferable to the situation of rheumatics, as they have a cascade of different regulatory disorders. Therefore, these approaches are not sufficient as the sole therapeutic measure for patients.

In addition to drug therapy, the promotion of physical activity in treatment is becoming increasingly important again [53]. In children and adolescents, this can be achieved with the help of conservative therapy. The central component here is physical therapy with simultaneous training in joint protection for the patient and parents. Often the basic rheumatological therapy is insufficiently available. For children and adolescents, in particular, to be able to participate in social life without any problems they also require specific advice on sports and other leisure activities. For example, alternatives to sports that put strain on the knee joint should be recommended (e.g., speed skating vs. ice hockey).

The prevalence of sarcopenia in rheumatics is about $20 \%$ and depends primarily on the age of the patient and his or her disability $[54,55]$. Thus, muscle training should be started and sustained as early as possible. An increase in physical activity leads to a decrease in inflammatory activity, whereby most studies are limited to the measurement of non-specific markers [56]. Already more than 20 years ago, a randomized study demonstrated an improvement in muscle strength through specific training with simultaneous pain reduction [57]. Gait analyses of rheumatic patients have shown a harmonization of the gait pattern in all phases under effective therapy with DMARDs [58]. Most studies, however, only deal with biomechanical characteristics of the knee joint after its endo-prosthetic treatment.

Newer studies recommend an early clarification of accompanying psychological problems since rheumatics are relatively more strongly impaired here than comparable collectives of arthritics [59]. It is up to the empathy of the doctor to be able to address this and initiate specific help. Unfortunately, out of false shame and insecurity, the treatment is usually limited to organic suffering.

If oligo-arthritis is present, in addition to physiotherapy and muscle training, decongestant measures such as cryotherapy and sonophoresis can be added. The intra-articular application of corticoids is increasingly viewed critically. Even local application increases the risk of secondary infection in immunomodulated patients. On the other hand, even low doses of cortisone seem to have long-term negative effects on bone metabolism. In animal models, osteomalacia can be detected in young rats after cortisone administration [60]. 


\section{Surgical Therapy}

In cases of persistent synovitis and an insufficient response to otherwise good drug therapy, the inflammatory mucosa should be removed. Synovectomy removes proinflammatory cytokines and simultaneously free nerve endings, which leads to a reduction in pain [61]. Today, arthroscopic synovectomy is considered standard therapy [62].

Surgical arthroscopic removal should also or especially be discussed in adolescents (Figures 1-3). The age limits for subsequent or, as an alternative, primary radio-synoviorthesis (RSO) have shifted to the front in recent years $[63,64]$. This is certainly also due to the lack of an alternative after the ban on chemical synoviorthesis [65-67].

Open joint-preserving procedures are now only used in special cases, such as arthrofibrosis with an inflammatory component.

Recurrences of synovitis are usually the result of a lack of radicality during surgery or a delay in follow-up therapy so that the remaining tissue can proliferate again. Therefore, an overall concept with therapy planning is essential even "beyond the day".

Before an operative intervention, an examination of the popliteal fossa and, if necessary, sonographic clarification should be performed to document the presence and extent of a Baker's cyst. MRI is reserved for special questions, such as the clarification of pigmented villonodular synovitis (hemosiderin deposits in the cell layer).

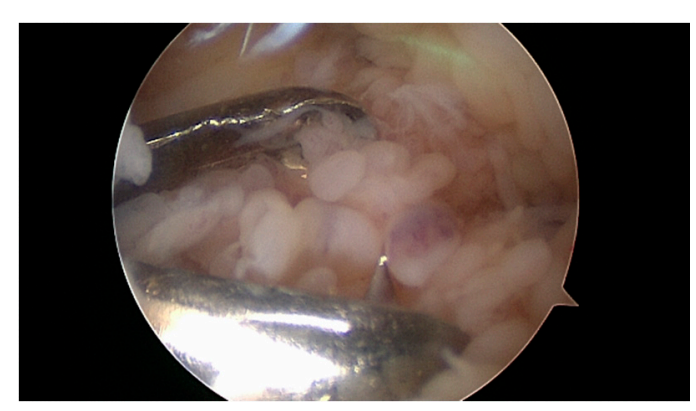

Figure 1. Synovial masses in the knee. 12-year-old boy with two years of symptomatic arthritis and insufficient medical treatment.

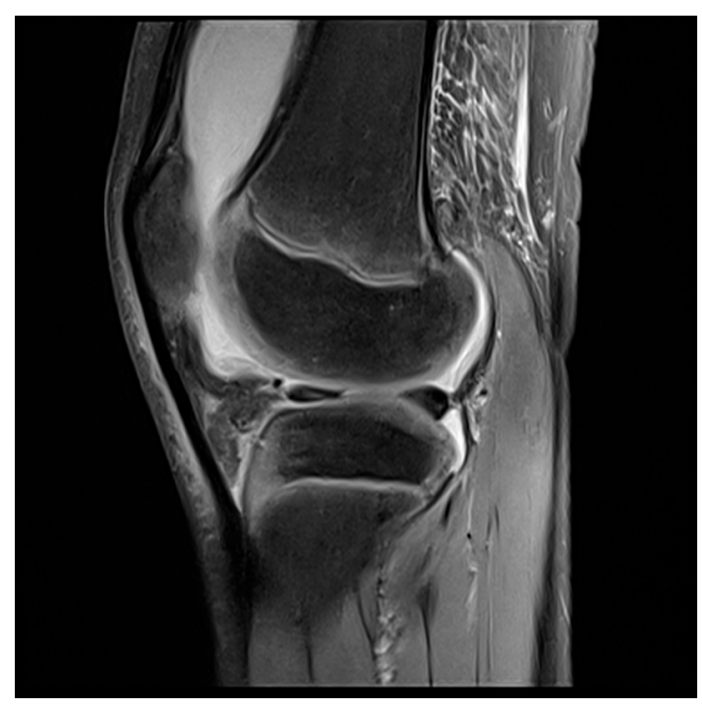

Figure 2. MRI knee of 12-year-old boy preoperative. 


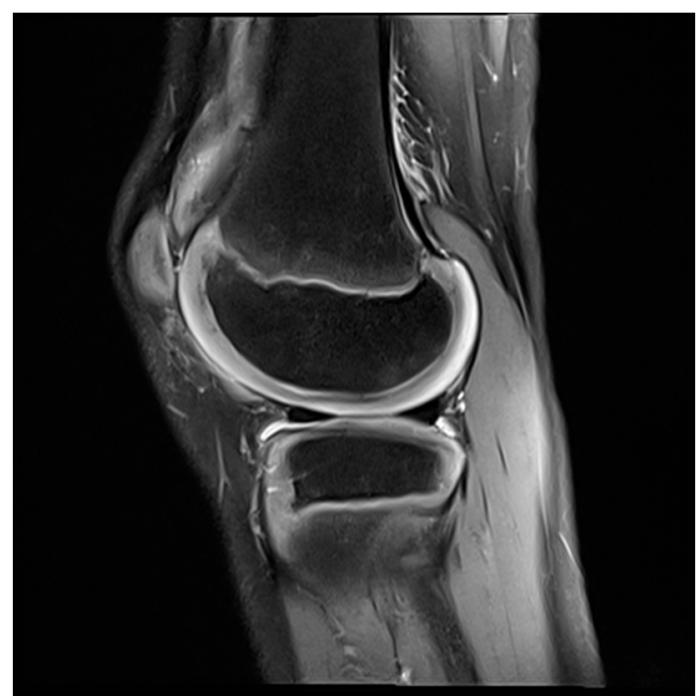

Figure 3. MRI knee of 12-year-old boy, three months after arthroscopic synovectomy.

The rheumatologically experienced surgeon should know alternative approaches, such as subvastus approach [68]. Delayed healing should be taken into account in postoperative therapy and mobilization. In most cases, the preference for stability over mobility is the better choice for rheumatics. In the long term, rheumatoid joints tend to lose tension in the course of the disease due to the above-mentioned involvement of the periarticular structures in the disease process. This must also be taken into account in endo-prosthetic treatment.

Once initiated, the destruction of the joint surfaces proceeds progressively as a result of increased local inflammatory activity [69]. Even after synovectomy and appropriate basic therapy, further damage can be detected on MRI [19]. The body's repair mechanisms are insufficient since they consist of inferior bone and fibrous cartilage. Chondroprotective or reconstructive procedures in rheumatics are limited to micro fracturing and denervation at the cartilage-bone interface.

\section{Joint Replacement Therapy/Endo-Prosthetic Treatment}

In case of advanced destruction of the joint surfaces, endo-prosthetic treatment is indicated. Surface replacement is also considered the gold standard for rheumatics. The widespread recommendation among arthroplasty patients to wait until an advanced age before fitting the prosthesis cannot be given to rheumatics. Rather a "wait and see" leads to destroyed and unstable knee joints and with young rheumatoid persons leads more quickly to the wheelchair obligation [70]. However, adequate basic therapy is and remains a basic requirement and without it, no surgical treatment is possible [71].

Very often, zones of severely sclerosed bone are found in inflammatory destroyed joints next to highly osteoporotic rarefied areas. In this case, fractures or bony tears of the collateral ligament attachments may occur during synovectomy. These are addressed intra-operatively and the knee joint is then fitted with a temporary orthosis. If the joint is so severely destroyed that the collateral ligaments do not allow stable guidance, axis-guided prostheses should be used. In the postoperative course, however, a periprosthetic fatigue fracture may still occur, in which a change of prosthesis is not always necessary, but stable osteosynthesis may be a sensible therapeutic option. The overall situation with the compensation options must always be considered.

The treatment of a rheumatoid knee joint with a unicondylar prosthesis is only rarely possible since the capsuloligamentous situation is usually already severely damaged. Dierkes et al. were able to present good long-term results with unicompartmental treatment in conjunction with radical synovectomy [72]. The retropatellar joint surface should not be treated with an endoprosthesis. The risk of early loosening with patella fracture and free cement portions, which can cause damage to the PE of 
the prosthesis, is too great. An alternative is to cover the patellar joint surface with a capsule flap as a patella-resection interposition arthroplastic (RIAP) [73].

In the case of rheumatoid knee joints, the long-term kinematics of the ligament and tendon structures should be taken into account when implanting a prosthesis. Careful balancing is crucial for the long-term success of the operation [74,75]. For this reason, minimal invasive treatment is considered a risk factor. Due to the synovial stretching of the capsule, rheumatics tend to subsequently loosen the ligament connections, so that tighter implantation of the surface replacement is the primary goal. Full-extension in the joint is achieved by active and passive physiotherapy of the joint. Orthopedic surgeons and trauma surgeons who do not have a unit trained in the specifics of rheumatism should tend to use a ligament-relieving, (partially) coupled prosthesis during surgery if the ligament is critical [1]. For the survival of the endoprosthesis in situ, the complete and meticulous synovectomy during primary surgery is and remains decisive, especially for rheumatics $[70,76]$.

Contractures of the collateral ligaments can be corrected using femoral osteotomy and screw fixation [1], but even minor traumas are sufficient to damage previously damaged soft tissue structures. If the intraoperative reconstruction is not successful, only a partially coupled or axis-guided implant remains. Reconstruction should always be attempted, particularly with younger patients, to maintain the possibility of withdrawal [77].

The disturbed interaction of the cells of the bone metabolism leads to a decrease in bone density, which is further reduced by cortisone medication in basic therapy. Osteoporosis is associated with an increased fracture rate. Comparable results have been shown in animal models [60]. The metaphysis is particularly susceptible to osteoporotic changes and usually exhibits poor bone quality with an increased risk of fracture [78]. If a fracture occurs, the stability of the endoprosthesis must be clarified primarily, since this is the basis for the surgical treatment. Either the joint can be left as it is and the fracture is treated with osteosynthesis (stable-angle plate, retrograde femoral nail) or by changing the knee prosthesis to an axis-guided model. In the case of periprosthetic fractures with shortening and axial malalignment of the leg, skin-penetrating fixations (external fixator, wire extensions) should nevertheless be avoided, since anchoring in the bone is poor and the secondary risk of infection is significantly increased in immunocompromised patients. Overall, the complication rate in RA is 2.5 times higher than in osteoarthritic patients, and restrictions in range of motion (ROM) up to 4 times higher. An improvement in function and activity also leads to an improvement in sarcopenia in the long term $[77,79]$.

Postoperatively, pain or pushing situations can occur, which are usually more stressful for the patient than the operation itself. The rheumatism sufferer can usually distinguish the operation-related pain quality very well from the usual inflammation-related pain.

While until a few years ago a cortisone regimen was still common, this now seems obsolete. The recommendation of German Society of Rheumatology (DGRh) still exists to pause the basic therapy with biologicals for two half-lives after the operation. Depending upon the individual situation, one deviates from it in order to get the rheumatic activity again under control. To what extent the perioperative administration of biologicals can be modified in the future will be answered by the complication register of the German Society of Orthopedic Rheumatology (DGORh) [43].

Patient satisfaction with the therapy depends on the pain projected into the knee joint [80]. A precise anamnesis and the identification of the pain site by the patient are important for further treatment. Often, ligamentous or ring-shaped pain is predominant in the area of the proximal tibia. In most cases, there is a simultaneous extension deficit with the overload of the proprio- and nociceptors of the knee joint. Dorsal expansion of the shortened contractile elements leads to a reduction of the retro-patellar contact pressure and pain reduction.

Punctual complaints indicate a local irritation of the infra-patellaris nerve or a suture granuloma. These can be verified and treated by local infiltration with local anesthetics.

In principle, ventral knee complaints after endo-prosthetic treatment can best be avoided by selecting and implanting suitable knee prosthesis systems that minimize the retro-patellar contact pressure both 
statically and dynamically [81]. Studies on the various endoprosthesis models show no significant differences in gait analysis, mobile or rigid platforms have a similar long-term outcome [82-85].

\section{Conclusions}

Inflammatory destructed knee joints are a common reason for severe impairments in the daily life of rheumatoid knees. The instability is not exclusively based on damage to the synovia, but also occurs through direct damage to the periarticular structures. Once triggered, the joint involvement results in long-term destruction. Before the implantation of an endoprosthesis, the whole range of conservative therapies should be used. This should not be limited to medical therapy alone, even though great progress has been made in recent years. In case of persistent synovitis, surgical synovectomy is still the adequate therapy of choice. Without adequate basic therapy, the success of the operation is limited. The knowledge about the care of rheumatics with all its facets and dangers ultimately also benefits all patients.

Author Contributions: C.B. writing—original draft preparation; C.B., M.H., L.B., G.K., C.H. and U.T. writing - review and editing. All authors have read and agree to the published version of the manuscript.

Funding: There is no source of funding. This research received no specific grant from any funding agency in the public, commercial, or not-for-profit sectors.

Acknowledgments: The authors thank Heiner Thabe for the opportunity to give his experience in the medical care of rheumatoid patients in general and in this topic.

Conflicts of Interest: The authors declare that there is no conflict of interest. This article does not include studies in humans or animals. The authors have previously published articles on similar topics.

\section{References}

1. Rehart, S.; Sell, S.; Arbogast, M.; Aringer, M.; Arnold, I. Expertise Orthopädische Rheumatologie; Georg Thieme Verlag: New York, NY, USA, 2015.

2. Chen, Z.; Bozec, A.; Ramming, A.; Schett, G. Anti-inflammatory and immune-regulatory cytokines in rheumatoid arthritis. Nat. Rev. Rheumatol. 2019, 15, 9-17. [CrossRef] [PubMed]

3. Mateen, S.; Zafar, A.; Moin, S.; Khan, A.Q.; Zubair, S. Understanding the role of cytokines in the pathogenesis of rheumatoid arthritis. Clin. Chim. Acta 2016, 455, 161-171. [CrossRef] [PubMed]

4. Baboolal, T.G.; Mastbergen, S.C.; Jones, E.; Calder, S.J.; Lafeber, F.P.; McGonagle, D. Synovial fluid hyaluronan mediates MSC attachment to cartilage, a potential novel mechanism contributing to cartilage repair in osteoarthritis using knee joint distraction. Ann. Rheum. Dis. 2016, 75, 908-915. [CrossRef] [PubMed]

5. Gaulke, R. Orthopädisch-Rheumatologische Jahresuntersuchung (ORJ). Z. Orthopädie Unf. 2018, 156, 505-508. [CrossRef] [PubMed]

6. Larsen, A.; Dale, K.; Eek, M. Radiographic Evaluation of Rheumatoid Arthritis and Related Conditions by Standard Reference Films. Acta Radiol. Diagn. 1977, 18, 481-491. [CrossRef]

7. Biehl, C.; Thormann, U.; Heiß, C. Complications in Knee Surgery of Rheumatic Patients. Aktuelle Rheumatol. 2016, 43, 73-81. [CrossRef]

8. Schöniger, A.; Henniger, M.; Rehart, S. Gelenkinfektionen in der orthopädischen Rheumatologie. OUP 2013, 2, 396-399. [CrossRef]

9. Liberati, A.; Altman, D.G.; Tetzlaff, J.; Mulrow, C.; Gøtzsche, P.C.; Ioannidis, J.P.; Clarke, M.; Devereaux, P.J.; Kleijnen, J.; Moher, D. The PRISMA Statement for Reporting Systematic Reviews and Meta-Analyses of Studies That Evaluate Health Care Interventions: Explanation and Elaboration. PLoS Med. 2009, 6, e1000100. [CrossRef]

10. De Lange-Brokaar, B.J.; Kloppenburg, M.; Andersen, S.N.; Dorjée, A.L.; Yusuf, E.; Herb-van Toorn, L.; Kroon, H.M.; Zuurmond, A.M.; Stojanovic-Susulic, V.; Bloem, J.L.; et al. Characterization of synovial mast cells in knee osteoarthritis: Association with clinical parameters. Osteoarthr. Cartil. 2016, 24, 664-671. [CrossRef]

11. Ouboussad, L.; Burska, A.N.; Melville, A.; Buch, M.H. Synovial Tissue Heterogeneity in Rheumatoid Arthritis and Changes With Biologic and Targeted Synthetic Therapies to Inform Stratified Therapy. Front. Med. 2019, 6, 45. [CrossRef] 
12. Cecchi, I.; De La Rosa, I.A.; Menegatti, E.; Roccatello, D.; Collantes-Estevez, E.; Lopez-Pedrera, C.; Barbarroja, N. Neutrophils: Novel key players in Rheumatoid Arthritis. Current and future therapeutic targets. Autoimmun. Rev. 2018, 17, 1138-1149. [CrossRef] [PubMed]

13. Smallwood, M.J.; Nissim, A.; Knight, A.R.; Whiteman, M.; Haigh, R.; Winyard, P.G. Oxidative stress in autoimmune rheumatic diseases. Free Radic. Biol. Med. 2018, 125, 3-14. [CrossRef] [PubMed]

14. Robinson, W.H.; Lepus, C.M.; Wang, Q.; Raghu, H.; Mao, R.; Lindstrom, T.M.; Sokolove, J. Low-grade inflammation as a key mediator of the pathogenesis of osteoarthritis. Nat. Rev. Rheumatol. 2016, 12, 580-592. [CrossRef] [PubMed]

15. Veselinovic, M.; Barudzic, N.; Vuletic, M.; Zivkovic, V.; Tomic-Lucic, A.; Djuric, D.; Jakovljević, V. Oxidative stress in rheumatoid arthritis patients: Relationship to diseases activity. Mol. Cell. Biochem. 2014, 391, 225-232. [CrossRef]

16. Lin, Y.-J.; Anzaghe, M.; Schülke, S. Update on the Pathomechanism, Diagnosis, and Treatment Options for Rheumatoid Arthritis. Cells 2020, 9, 880. [CrossRef]

17. Najm, A.; Le Goff, B.; Orr, C.; Thurlings, R.; Canete, J.D.; Humby, F.; Alivernini, S.; Manzo, A.; Just, S.A.; Romao, V.C.; et al. Standardisation of synovial biopsy analyses in rheumatic diseases: A consensus of the EULAR Synovitis and OMERACT Synovial Tissue Biopsy Groups. Arthritis Res. Ther. 2018, 20, 265. [CrossRef]

18. Carmona-Rivera, C.; Carlucci, P.M.; Moore, E.; Lingampalli, N.; Uchtenhagen, H.; James, E.; Liu, Y.; Bicker, K.L.; Wahamaa, H.; Hoffmann, V.; et al. Synovial fibroblast-neutrophil interactions promote pathogenic adaptive immunity in rheumatoid arthritis. Sci. Immunol. 2017, 2, eaag3358. [CrossRef]

19. Hirose, J.; Nishioka, H.; Tsukano, M.; Matsubara, S.; Usuku, K.; Mizuta, H. Matrix changes in articular cartilage in the knee of patients with rheumatoid arthritis after biological therapy: 1-year follow-up evaluation by T2 and T1 $\rho$ MRI quantification. Clin. Radiol. 2018, 73, 984.e911-984.e918. [CrossRef]

20. Bottini, N.; Firestein, G.S. Duality of fibroblast-like synoviocytes in RA: Passive responders and imprinted aggressors. Nat. Rev. Rheumatol. 2013, 9, 24-33. [CrossRef]

21. Harre, U.; Schett, G. Association between bone catabolism and anti-citrullinated protein antibodies in rheumatoid arthritis. Z. Rheumatol. 2016, 75, 809-811. [CrossRef] [PubMed]

22. Davis, L.S.; Cush, J.J.; Schulze-Koops, H.; Lipsky, P.E. Rheumatoid synovial CD4+ T cells exhibit a reduced capacity to differentiate into IL-4-producing T-helper-2 effector cells. Arthritis Res. 2001, 3, 54-64. [CrossRef] [PubMed]

23. Conigliaro, P.; Triggianese, P.; De Martino, E.; Fonti, G.L.; Chimenti, M.S.; Sunzini, F.; Viola, A.; Canofari, C.; Perricone, R. Challenges in the treatment of Rheumatoid Arthritis. Autoimmun. Rev. 2019, 18, 706-713. [CrossRef] [PubMed]

24. Evangelatos, G.; Fragoulis, G.E.; Koulouri, V.; Lambrou, G.I. MicroRNAs in rheumatoid arthritis: From pathogenesis to clinical impact. Autoimmun. Rev. 2019, 18, 102391. [CrossRef]

25. Sardar, R.; Satish, D.; Gupta, D. Identification of Novel SARS-CoV-2 Drug Targets by Host MicroRNAs and Transcription Factors Co-regulatory Interaction Network Analysis. Front. Genet. 2020, 11, 571274. [CrossRef] [PubMed]

26. Takayanagi, H. Osteoimmunology: Shared mechanisms and crosstalk between the immune and bone systems. Nat. Rev. Immunol. 2007, 7, 292-304. [CrossRef] [PubMed]

27. Diller, M.; Hasseli, R.; Hülser, M.-L.; Aykara, I.; Frommer, K.; Rehart, S.; Müller-Ladner, U.; Neumann, E. Targeting Activated Synovial Fibroblasts in Rheumatoid Arthritis by Peficitinib. Front. Immunol. 2019, 10, 541. [CrossRef] [PubMed]

28. Meireles, S.M.; Oliveira, L.M.; Andrade, M.S.; Silva, A.C.; Natour, J. Isokinetic evaluation of the knee in patients with rheumatoid arthritis. Jt. Bone Spine 2002, 69, 566-573. [CrossRef]

29. Weiss, R.J.; Wretenberg, P.; Stark, A.; Palmblad, K.; Larsson, P.; Grondal, L.; Broström, E. Gait pattern in rheumatoid arthritis. Gait Posture 2008, 28, 229-234. [CrossRef]

30. Van Der Straaten, R.; Wesseling, M.; Jonkers, I.; Vanwanseele, B.; Bruijnes, A.; Malcorps, J.; Bellemans, J.; Truijen, J.; De Baets, L.; Timmermans, A. Functional movement assessment by means of inertial sensor technology to discriminate between movement behaviour of healthy controls and persons with knee osteoarthritis. J. Neuroeng. Rehabil. 2020, 17, 65. [CrossRef]

31. Kawamura, K.; Momohara, S.; Tomatsu, T. Alignment of lower extremity in rheumatoid arthritis patients with a history of both total hip replacement and total knee replacement. Ryumachi 2003, 43, 638-643. 
32. Imagama, T.; Tokushige, A.; Seki, K.; Taguchi, T. Weight Bearing Joints Destruction in Rheumatoid Arthritis. Curr. Rheumatol. Rev. 2017, 13, 37-42. [CrossRef] [PubMed]

33. Tittinger, T.; Słoniak, R.; Szczepański, D.; Gaździk, T.S.; Kulesa-Mrowiecka, M.; Kikowski, Ł. Lateral instability of the knee joint and disorder of the ankle joint extension disorder in men. Wiad. Lek. 2019, 72, 250-254. [CrossRef] [PubMed]

34. Nowotny, J.; Kasten, P. Physiologie der Sehnenheilung. Orthopädie Unf. Up2date 2015, 10, 75-87. [CrossRef]

35. Biehl, C.; Kappl, S.; Rehart, S. Operative Therapie an den Gelenken bei der Spondyloarthritis. Aktuelle Rheumatol. 2013, 38, 104-108. [CrossRef]

36. Goodman, S.M.; Springer, B.; Guyatt, G.; Abdel, M.P.; Dasa, V.; George, M.D.; Gewurz-Singer, O.; Giles, J.T.; Johnson, B.; Lee, S.; et al. 2017 American College of Rheumatology/American Association of Hip and Knee Surgeons Guideline for the Perioperative Management of Antirheumatic Medication in Patients With Rheumatic Diseases Undergoing Elective Total Hip or Total Knee Arthroplasty. Arthritis Rheumatol. 2017, 69, 1538-1551. [CrossRef] [PubMed]

37. Smolen, J.S.; Aletaha, D.; Barton, A.; Burmester, G.R.; Emery, P.; Firestein, G.S.; Kavanaugh, A.; McInnes, I.B.; Solomon, D.H.; Strand, V.; et al. Rheumatoid arthritis. Nat. Rev. Dis. Prim. 2018, 4, 18001. [CrossRef]

38. Smolen, J.S.; Landewé, R.B.M.; Bijlsma, J.W.J.; Burmester, G.R.; Dougados, M.; Kerschbaumer, A.; McInnes, I.B.; Sepriano, A.; Van Vollenhoven, R.F.; De Wit, M.; et al. EULAR recommendations for the management of rheumatoid arthritis with synthetic and biological disease-modifying antirheumatic drugs: 2019 Update. Ann. Rheum. Dis. 2020, 79, 685-699. [CrossRef]

39. Goodman, S.M.; George, M.D. Should we stop or continue conventional synthetic (including glucocorticoids) and targeted DMARDs before surgery in patients with inflammatory rheumatic diseases? RMD Open 2020, 6, e001214. [CrossRef]

40. George, M.D.; Baker, J.F. Perioperative management of immunosuppression in patients with rheumatoid arthritis. Curr. Opin. Rheumatol. 2019, 31, 300-306. [CrossRef]

41. Yeganeh, M.H.; Kheir, M.M.; Shahi, A.; Parvizi, J. Rheumatoid Arthritis, Disease Modifying Agents, and Periprosthetic Joint Infection: What Does a Joint Surgeon Need to Know? J. Arthroplast. 2018, 33, 1258-1264. [CrossRef]

42. Krüger, K.; Der Dgrh, K.P.; Albrecht, K.; Rehart, S.; Scholz, R. Empfehlungen der Deutschen Gesellschaft für Rheumatologie zur perioperativen Vorgehensweise unter Therapie mit DMARD und Biologicals bei entzündlich-rheumatischen Erkrankungen. Z. Rheumatol. 2014, 73, 77-84. [CrossRef]

43. Kostuj, T.; Rehart, S.; Matta-Hurtado, R.; Biehl, C.; Willburger, R.E.; Schmidt, K. Pilot study for the registry of complications in rheumatic diseases from the German Society of Surgery (DGORh): Evaluation of methods and data from the first 1000 patients. BMJ Open 2017, 7, e015987. [CrossRef]

44. Kobayashi, S.; Niki, Y.; Harato, K.; Nagura, T.; Nakamura, M.; Matsumoto, M. Rheumatoid Arthritis Patients Achieve Better Satisfaction but Lower Functional Activities as Compared to Osteoarthritis Patients After Total Knee Arthroplasty. J. Arthroplast. 2019, 34, 478-482.e1. [CrossRef] [PubMed]

45. Rahimnia, A.; Alishiri, G.; Bayatpoor, M.E.; Hosseini, M.A.; Najafizadeh-Sari, S.; Yaribeygi, H.; Sahebkar, A. Evaluation of Disease Severity and Health-Related Quality of Life in Patients with Rheumatoid Arthritis Undergoing Total Knee Arthroplasty. Curr. Rheumatol. Rev. 2020, 16, 1-8. [CrossRef] [PubMed]

46. Khanna, S.; Jaiswal, K.S.; Gupta, B. Managing Rheumatoid Arthritis with Dietary Interventions. Front. Nutr. 2017, 4, 52. [CrossRef] [PubMed]

47. Cordaro, M.; Siracusa, R.; Impellizzeri, D.; D'Amico, R.; Peritore, A.F.; Crupi, R.; Gugliandolo, E.; Fusco, R.; Di Paola, R.; Schievano, C.; et al. Safety and efficacy of a new micronized formulation of the ALIAmide palmitoylglucosamine in preclinical models of inflammation and osteoarthritis pain. Arthritis Res. 2019, 21, 254. [CrossRef] [PubMed]

48. Di Pietro, V.; Yakoub, K.M.; Caruso, G.; Lazzarino, G.; Signoretti, S.; Barbey, A.K.; Tavazzi, B.; Lazzarino, G.; Belli, A.; Amorini, A.M. Antioxidant Therapies in Traumatic Brain Injury. Antioxidants 2020, 9, 260. [CrossRef] [PubMed]

49. Dudics, S.; Langan, D.; Meka, R.R.; Venkatesha, S.H.; Berman, B.M.; Che, C.-T.; Moudgil, K.D. Natural Products for the Treatment of Autoimmune Arthritis: Their Mechanisms of Action, Targeted Delivery, and Interplay with the Host Microbiome. Int. J. Mol. Sci. 2018, 19, 2508. [CrossRef]

50. Izzi, V.; Masuelli, L.; Tresoldi, I.; Sacchetti, P.; Modesti, A.; Galvano, F.; Bei, R. The effects of dietary flavonoids on the regulation of redox inflammatory networks. Front. Biosci. Landmark Ed. 2012, 17, 2396-2418. [CrossRef] 
51. Bang, J.S.; Oh, D.H.; Choi, H.M.; Sur, B.J.; Lim, S.J.; Kim, J.Y.; Yang, H.I.; Yoo, M.C.; Hahm, D.H.; Kim, K.S. Anti-inflammatory and antiarthritic effects of piperine in human interleukin $1 \beta$-stimulated fibroblast-like synoviocytes and in rat arthritis models. Arthritis Res. Ther. 2009, 11, R49. [CrossRef]

52. Richardson, D.; Pearson, R.G.; Kurian, N.; Latif, M.L.; Garle, M.J.; Barrett, D.A.; Kendall, D.A.; Scammell, B.E.; Reeve, A.J.; Chapman, V. Characterisation of the cannabinoid receptor system in synovial tissue and fluid in patients with osteoarthritis and rheumatoid arthritis. Arthritis Res. Ther. 2008, 10, R43. [CrossRef] [PubMed]

53. Osthoff, A.K.R.; Niedermann, K.; Braun, J.; Adams, J.; Brodin, N.; Dagfinrud, H.; Duruoz, T.; Esbensen, B.A.; Günther, K.-P.; Hurkmans, E.; et al. 2018 EULAR recommendations for physical activity in people with inflammatory arthritis and osteoarthritis. Ann. Rheum. Dis. 2018, 77, 1251-1260. [CrossRef] [PubMed]

54. Barone, M.; Viggiani, M.T.; Anelli, M.G.; Fanizzi, R.; Lorusso, O.; Lopalco, G.; Cantarini, L.; Di Leo, A.; Lapadula, G.; Iannone, F. Sarcopenia in Patients with Rheumatic Diseases: Prevalence and Associated Risk Factors. J. Clin. Med. 2018, 7, 504. [CrossRef]

55. Ngeuleu, A.; Allali, F.; Medrare, L.; Madhi, A.; Rkain, H.; Hajjaj-Hassouni, N. Sarcopenia in rheumatoid arthritis: Prevalence, influence of disease activity and associated factors. Rheumatol. Int. 2017, 37, 1015-1020. [CrossRef] [PubMed]

56. Dreher, M.; Kosz, M.; Schwarting, A. Physical activity, exercise and nutrition in rheumatism: Adjuvant treatment options for inflammatory-rheumatic diseases. Orthopade 2019, 48, 917-926. [CrossRef]

57. McMeeken, J.; Stillman, B.; Story, I.; Kent, P.; Smith, J. The effects of knee extensor and flexor muscle training on the timed-up-and-go test in individuals with rheumatoid arthritis. Physiother. Res. Int. 1999, 4, 55-67. [CrossRef]

58. Oda, R.; Fujiwara, H.; Tokunaga, D.; Nakamura, S.; Taniguchi, D.; Kawahito, Y.; Seno, T.; Matsui, T.; Kubo, T. How do anti-TNF therapies affect gait function in patients with rheumatoid arthritis? Int. J. Rheum. Dis. 2013, 17, 57-62. [CrossRef] [PubMed]

59. Pu, D.; Luo, J.; Wang, Y.; Ju, B.; Lv, X.; Fan, P.; He, L. Prevalence of depression and anxiety in rheumatoid arthritis patients and their associations with serum vitamin D level. Clin. Rheumatol. 2018, 37, 179-184. [CrossRef]

60. Bauer, N.B.; Khassawna, T.E.; Goldmann, F.; Stirn, M.; Ledieu, D.; Schlewitz, G.; Govindarajan, P.; Zahner, D.; Weisweiler, D.; Schliefke, N.; et al. Characterization of bone turnover and energy metabolism in a rat model of primary and secondary osteoporosis. Exp. Toxicol. Pathol. 2015, 67, 287-296. [CrossRef]

61. Dusad, A.; Pedro, S.; Mikuls, T.R.; Hartman, C.W.; Garvin, K.L.; O’Dell, J.R.; Michaud, K. Impact of Total Knee Arthroplasty as Assessed Using Patient-Reported Pain and Health-Related Quality of Life Indices: Rheumatoid Arthritis Versus Osteoarthritis. Arthritis Rheumatol. 2015, 67, 2503-2511. [CrossRef]

62. Lipina, M.; Makarov, M.; Mukhanov, V.; Karpashevich, A.; Maglevaniy, S.; Amirdjanova, V.; Archipov, S. Arthroscopic synovectomy of the knee joint for rheumatoid arthritis. Int. Orthop. 2019, 43, 1859-1863. [CrossRef] [PubMed]

63. Kerschbaumer, F.; Kandziora, F.; Herresthal, J.; Hertel, A.; Hör, G. Combined arthroscopic and radiation synovectomy in rheumatoid arthritis. Orthopade 1998, 27, 188-196. [CrossRef] [PubMed]

64. Maderbacher, G.; Greimel, F.; Schaumburger, J.; Grifka, J.; Baier, C. The knee joint in rheumatoid arthritis-current orthopaedic surgical treatment options. Z. Rheumatol. 2018, 77, 882-888. [CrossRef] [PubMed]

65. Chalmers, P.N.; Sherman, S.L.; Raphael, B.S.; Su, E.P. Rheumatoid Synovectomy: Does the Surgical Approach Matter? Clin. Orthop. Relat. Res. 2011, 469, 2062-2071. [CrossRef] [PubMed]

66. Beil, F.T.; Ruther, W. Indications and contraindications for radiosynoviorthesis. Z. Rheumatol. 2015, 74, 780-785. [CrossRef] [PubMed]

67. Carl, H.D.; Swoboda, B. Effectiveness of arthroscopic synovectomy in rheumatoid arthritis. Z. Rheumatol. 2008, 67, 485-490. [CrossRef]

68. Wirth, C.J.; Kerschbaumer, F.; Weise, K.U. Operative Zugangswege in Orthopädie und Traumatologie: Begründet von Rudolf Bauer, Fridun Kerschbaumer und Sepp Poisel; Thieme: New York, NY, USA, 2013.

69. Krenn, V.; Morawietz, L.; Burmester, G.R.; Haupl, T. Synovialitis score: Histopathological grading system for chronic rheumatic and non-rheumatic synovialitis. Z. Rheumatol. 2005, 64, 334-342. [CrossRef]

70. Carl, H.D.; Gelse, K.; Swoboda, B. Total knee arthroplasty for rheumatoid arthritis. Z. Rheumatol. 2011, 70, 411-416. [CrossRef]

71. Mirza, R.; Ishaq, S.; Khan, M.O.; Memon, A. Rituximab therapy for flare-up of rheumatoid arthritis after total knee replacement surgery. J. Pak. Med. Assoc. 2012, 62, 1120-1123. 
72. Dierkes, B.; Oda, A.; Thabe, H. [Long- and medium-term results after unicondylar prosthesis at the knee joint in patients with RA.]. In Proceedings of the 37th Congress of the German Society of Rheumatology, Cologne, Germany, 23-26 September 2009.

73. Thabe, H.; Brackertz, D. Praktische Rheumaorthopädie; Chapman and Hall: London, UK, 1997.

74. Wang, W.; Niu, D. Balancing of soft tissues in total knee arthroplasty for patients with rheumatoid arthritis with knee flexion contracture. Zhongguo Xiu Fu Chong Jian Wai Ke Za Zhi 2008, 22, 1173-1176.

75. Hou, H.B.; Cao, B.; Shi, S.M.; Huo, A.X.; Liu, Y.H. Total knee arthroplasty for treatment of rheumatoid arthritis: A protocol for a systematic review of randomized controlled trial. Medicine 2019, 98, e16558. [CrossRef] [PubMed]

76. Fink, B.; Berger, I.; Siegmüller, C.; Fassbender, H.-G.; Meyer-Scholten, C.; Tillmann, K.; Rüther, W. Recurring synovitis as a possible reason for aseptic loosening of knee endoprostheses in patients with rheumatoid arthritis. J. Bone Jt. Surg. 2001, 83, 604-608. [CrossRef]

77. Li, Z.; Feng, B.; Du, Y.; Wang, Y.; Bian, Y.; Weng, X. Complications of total knee arthroplasty in patients with haemophilia compared with osteoarthritis and rheumatoid arthritis: A 20-year single-surgeon cohort. Haemophilia 2020, 26, 861-866. [CrossRef] [PubMed]

78. Murahashi, Y.; Teramoto, A.; Jimbo, S.; Okada, Y.; Kamiya, T.; Imamura, R.; Takashima, H.; Watanabe, K.; Nagoya, S. Denosumab prevents periprosthetic bone mineral density loss in the tibial metaphysis in total knee arthroplasty. Knee 2020, 27, 580-586. [CrossRef]

79. Kumagai, K.; Harigane, K.; Kusayama, Y.; Tezuka, T.; Inaba, Y.; Saito, T. Total knee arthroplasty improves both knee function and disease activity in patients with rheumatoid arthritis. Mod. Rheumatol. 2017, 27, 806-810. [CrossRef]

80. Thiele, K.; Fussi, J.; Perka, C.; Pfitzner, T. The Berlin diagnostic algorithm for painful knee TKA. Orthopade 2016, 45, 38-46. [CrossRef]

81. Thabe, H.; Dafferner-Franzmann, M.; Stening, J. Long-Term Results with Different Designs in Knee Replacements. Aktuelle Rheumatol. 2014, 39, 130-134. [CrossRef]

82. Van Hamersveld, K.T.; Marang-Van De Mheen, P.J.; Van Der Heide, H.J.L.; Van Der Linden-Van Der Zwaag, H.M.J.; Valstar, E.R.; Nelissen, R. Migration and clinical outcome of mobile-bearing versus fixed-bearing single-radius total knee arthroplasty. Acta Orthop. 2018, 89, 190-196. [CrossRef]

83. Wolterbeek, N.; Garling, E.H.; Mertens, B.; Valstar, E.R.; Nelissen, R.G. Mobile bearing knee kinematics change over time. A fluoroscopic study in rheumatoid arthritis patients. Clin. Biomech. 2009, 24, 441-445. [CrossRef]

84. Wolterbeek, N.; Nelissen, R.G.; Valstar, E.R. No differences in in vivo kinematics between six different types of knee prostheses. Knee Surg. Sports Traumatol. Arthrosc. Off. J. ESSKA 2012, 20, 559-564. [CrossRef]

85. Hofstede, S.N.; Nouta, K.A.; Jacobs, W.; van Hooff, M.L.; Wymenga, A.B.; Pijls, B.G.; Nelissen, R.G.; Marang-van de Mheen, P.J. Mobile bearing vs fixed bearing prostheses for posterior cruciate retaining total knee arthroplasty for postoperative functional status in patients with osteoarthritis and rheumatoid arthritis. Cochrane Database Syst. Rev. 2015, 2, CD003130. [CrossRef] [PubMed]

Publisher's Note: MDPI stays neutral with regard to jurisdictional claims in published maps and institutional affiliations.

(C) 2020 by the authors. Licensee MDPI, Basel, Switzerland. This article is an open access article distributed under the terms and conditions of the Creative Commons Attribution (CC BY) license (http://creativecommons.org/licenses/by/4.0/). 